Nat. Hazards Earth Syst. Sci., 18, 91-104, 2018

https://doi.org/10.5194/nhess-18-91-2018

(c) Author(s) 2018. This work is distributed under the Creative Commons Attribution 3.0 License.

\title{
Towards a monitoring system of temperature extremes in Europe
}

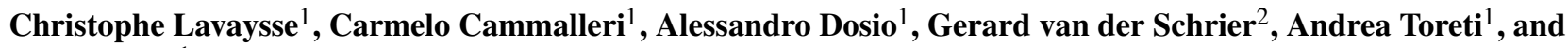 \\ Jürgen Vogt ${ }^{1}$ \\ ${ }^{1}$ European Commission, Joint Research Centre (JRC), Ispra, Italy \\ ${ }^{2}$ Royal Netherlands Meteorological Institute (KNMI), De Bilt, the Netherlands
}

Correspondence: Christophe Lavaysse (christophe.lavaysse@ec.europa.eu)

Received: 23 May 2017 - Discussion started: 29 May 2017

Revised: 17 October 2017 - Accepted: 17 October 2017 - Published: 5 January 2018

\begin{abstract}
Extreme-temperature anomalies such as heat and cold waves may have strong impacts on human activities and health. The heat waves in western Europe in 2003 and in Russia in 2010, or the cold wave in southeastern Europe in 2012, generated a considerable amount of economic loss and resulted in the death of several thousands of people. Providing an operational system to monitor extreme-temperature anomalies in Europe is thus of prime importance to help decision makers and emergency services to be responsive to an unfolding extreme event.

In this study, the development and the validation of a monitoring system of extreme-temperature anomalies are presented. The first part of the study describes the methodology based on the persistence of events exceeding a percentile threshold. The method is applied to three different observational datasets, in order to assess the robustness and highlight uncertainties in the observations. The climatology of extreme events from the last 21 years is then analysed to highlight the spatial and temporal variability of the hazard, and discrepancies amongst the observational datasets are discussed. In the last part of the study, the products derived from this study are presented and discussed with respect to previous studies. The results highlight the accuracy of the developed index and the statistical robustness of the distribution used to calculate the return periods.
\end{abstract}

\section{Introduction}

Extreme-temperature anomalies have strong impacts on human health and activities. The heat waves that occurred over western Europe in August 2003 caused about 70000 deaths across 12 countries (Robine et al., 2008). The heat wave in
Russia during the summer 2010, considered as the strongest in the last 30 years (Barriopedro et al., 2011; Russo et al., 2015), caused more than 55000 deaths and EUR 500 million of damage. In February 2012 a cold wave over central and eastern Europe generated more than EUR 700 million of damage, and 825 deaths were reported (de'Donato et al., 2013). Monitoring and cataloguing these events are crucial in order to place an event in its historical perspective and in order to assess the potential impacts on human health and activities by combining the information with data from other catalogues (such as EM-DAT, http://www.emdat.be, which includes information on the impacts). A catalogue would also be appropriate to analyse the spatial and temporal evolution of the hazard related to temperature anomalies, and, finally in the future, to calibrate and validate an operational forecasting system in terms of these extreme events. This product will be implemented in the operational monitoring system of the European Drought Observatory (EDO, http://edo.jrc.ec.europa.eu).

From the human health point of view, a heat (cold) wave can be considered as a period with sustained temperature anomalies resulting in one of a number of health outcomes, including mortality, morbidity and emergency service callout (Kovats et al., 2006). Wave intensity and duration, but also time of the year, are important determinants of the impact on health (Montero et al., 2012; Rocklov et al., 2012). While most studies focus on daytime conditions only, there is emerging evidence that nocturnal conditions can also play an important role in generating heat-related health effects, a result of the cumulative build-up of the heat load with little respite during the night (Rooney et al., 1998).

In the literature, some indicators have been developed to describe the complex conditions of heat exchange between 
the human body and its thermal environment. For warm conditions, indices usually consist of combinations of dry-bulb temperature and different measures for humidity or wind speed - such as the humidex (Smoyer-Tomic et al., 2003), the net effective temperature ( $\mathrm{Li}$ and Chan, 2000), the wetbulb globe temperature (Budd, 2009), the heat index (Steadman, 1979) or the apparent temperature (Steadman, 1984). More generally, efforts have been made to harmonize the large number of indices developed. For example, the Universal Thermal Climate Index (UTCI, www.utci.org) has been proposed to assess heat and cold waves. The main inconvenience of most of these indices is technical - i.e. the humidity when the daily maximum or daily minimum temperature (hereafter $T_{\max }$ and $T_{\min }$ ) occur is not necessarily known. In addition, the simulated values of wind speed and humidity provided by numerical weather models are generally less accurate than the $2 \mathrm{~m}$ temperature in the reanalysis and observational datasets. The WMO Expert Team on Climate Change Detection and Indices (ETCCDI) proposed the Warm Spell Duration Index (WSDI) as standard measurement of heat and cold waves, which is calculated using a percentile-based threshold. Russo et al. (2015) proposed a version of this method that provides the amplitude (or intensity) of a heat wave based on the maximum temperature and the interquartile range of yearly maximum temperatures of the past period. This method is powerful to compare the heat waves at climatological scale over the world and their trends with a local standardization. Nevertheless, this method is not suitable for monitoring heat waves because it focuses on the most extreme events (the thresholds are defined according to the yearly maxima), and it does not take into account the strong human impact of $T_{\min }$ (WMO, 2015).

In this study we propose an operational system to monitor heat and cold waves based on an adapted index inspired by the previous studies. In Sect. 2, data and methods are presented and the uncertainties related to the observations are assessed. Then, the climatology in terms of occurrence, intensity and duration of the waves are presented in Sect. 3. This represents the baseline of the monitoring system that will become operational and embedded in the EDO system. Finally, concluding remarks are provided in Sect. 4.

\section{Data and tools}

\subsection{Datasets}

In this study we use daily $T_{\max }$ and $T_{\min }$ from three different datasets. The first one is based on the $2 \mathrm{~m}$ temperature datasets provided by the European National Weather Services, which, in turn, is used as an input for the LisFlood hydrological model (De Roo et al., 2000). The observations are gridded onto a regular lat/long grid of one square degree. The use of gridded observation data makes it possible (i) to focus on large-scale heat/cold waves and (ii) to compare the station data with reanalysis data. This LisFlood product will be eventually used in the operational system for the monitoring of extreme-temperature waves. To validate the results, a comparison with two other sets of data is performed: the ERA-Interim reanalysis (ERAI, Dee et al., 2011) and the EOBS/ECAD dataset Version 14 (Haylock et al., 2008; van den Besselaar et al., 2011), both regridded to the same one square degree resolution. Note that, according to ECMWF, ERAI datasets are released with a delay of 2 months for quality assurance; as a consequence, this dataset cannot be used for operational monitoring purposes. The same problem occurs for the EOBS datasets.

The definition of $T_{\max }$ and $T_{\min }$ in the three datasets can differ from the definition of WMO (van den Basselaar et al., 2012). In LisFlood, the $T_{\min }$ assigned to the day $d$ is defined as the minimum temperature value that occurred from 18:00 local time (LT) of the day before $(d-1)$ to 06:00 LT of the day $d$. For EOBS, $T_{\min }$ is defined as the $24 \mathrm{~h}$ daily minimum. Similarly, $T_{\max }$ of the day $d$ is the maximum temperature recorded from 06:00 to 18:00LT of the day $d$ for LisFlood data and the $24 \mathrm{~h}$ daily maximum for EOBS. In ERAI, $T_{\min }$ $\left(T_{\max }\right)$ of day $d$ is the lowest (highest) value of temperatures recorded at 00:00, 06:00, 12:00 or 18:00 LT of day $d$. The starting years of the period covered by the datasets are also different (1950 for EOBS, 1979 for ERAI and 1990 for LisFlood). In order to be consistent and in view of the future use for the re-forecast period of the ECMWF ENS forecast model, the period from 1995 to 2015 (21 years) is used for all the datasets. Note that most of the results obtained in this study have been compared to a longer period (starting from 1990) providing very similar results. According to WMO (2009), the recommended durations of climate samples depend on the purpose of the study: climate evolution, detection of extremes, climatological reference, climatological evolution of extremes, etc. However, there is no clear consensus about a specific duration. As the purpose of this monitoring system is the detection of relatively intense events according to a reference period, we consider that 20 years is sufficient to provide a robust climatology. This baseline duration is used in plenty of studies/datasets (Kharin et al., 2013; Vautard et al., 2013; Monhart et al., 2016). It is also worth noting that ECMWF runs an extended ensemble model with hindcast (or re-forecast) to create a climatological baseline to correct the model bias, build a climatology and detect the strongest anomalies (Vitart, 2004). These hindcasts are also performed using 21 years, highlighting the usefulness of this length of climatological reference. Moreover, the use of a longer period of sampling to estimate the climatology and to calculate the return period could underestimate the actual return periods of the events due to the non-stationarity of the occurrences and intensities of heat and cold waves in the context of climate change (Gonzales-Hidalgo et al., 2016). According to the WMO guideline (WMO, 2009) and the mentioned previous studies, but also (i) due to the availability of the datasets and (ii) to be consistent with the forecasts that 
will be implemented in the same system in the future, we decided to use the 21-year climatology to detect and characterize the intensities of heat and cold waves.

\subsection{Metric of extreme-temperature anomalies}

Following the WMO definition, there are many different ways to measure a heat wave (Perkins et al., 2013). The objective of this study is not to create a new index, but to provide an operational system based on an adapted method proposed in the literature. This system is inspired by the studies of Russo et al. (2014) and WMO (2015). First, daily $T_{\min }$ and $T_{\max }$ are transformed into quantiles based on the climatological (21 years) calendar percentiles of each variable. To highlight the events with the most potential human impact, the year is split into two periods: the extended summer period, when heat waves usually have stronger impacts (the six hottest months over Europe, from April to September), and the extended winter period to focus on the cold waves (from October to March). Note that also during the summer (winter) period, cold (heat) waves may occur but they are not considered here. The independent calculation of the daily quantiles of observed $T_{\min }$ and $T_{\max }$ is done by applying a leave-one-out method to avoid inhomogeneities (Zhang et al., 2005). The year studied is removed from the climatology. The data without this year is used to derive the observed cumulative distribution function (CDF). To remove artefacts due to the relative small sampling (21 years), a window of 11 days centred on the day studied is exploited. The daily temperatures are transformed into quantiles by this procedure to create two daily temperature quantiles from 1995 to 2015, derived from the CDF of $T_{\min }$ and $T_{\max }$ independently.

The main difference from previous studies is the use of both $T_{\max }$ and $T_{\min }$, rather than $T_{\max }$ only or the daily mean temperature. Thus, a hot day is defined when simultaneously the daily quantiles of $T_{\max }$ and $T_{\min }$ are above quantile 0.9 during the extended summer (from April to September). The same definition is applied for cold days when the two quantiles are lower than quantile 0.1 from October to March. The occurrences are strongly influenced by these thresholds. As this study aims at quantifying the intensity of waves regarding the climatology and at assessing with robust scores the forecast of these events, it is not possible to focus only on the most extreme cases. So these thresholds (quantiles 0.9 and 0.1 ) are chosen as a compromise between the need to have a minimum number of events and the definition of extremes. They are also used in a large number of other studies (WMO, 2015, Hirschi et al., 2011). Note that in order to discuss the sensitivity of using the intersection of $T_{\min }$ and $T_{\max }$ rather than one temperature value per day, the same methodology has also been applied using separately $T_{\min }$ and $T_{\max }$ to determine hot and cold days.

Heat and cold waves are associated with a persistence of hot or cold days. Based on the literature (Gasparrini and Armstrong, 2011; Kuglitsch et al., 2010), as well as on the

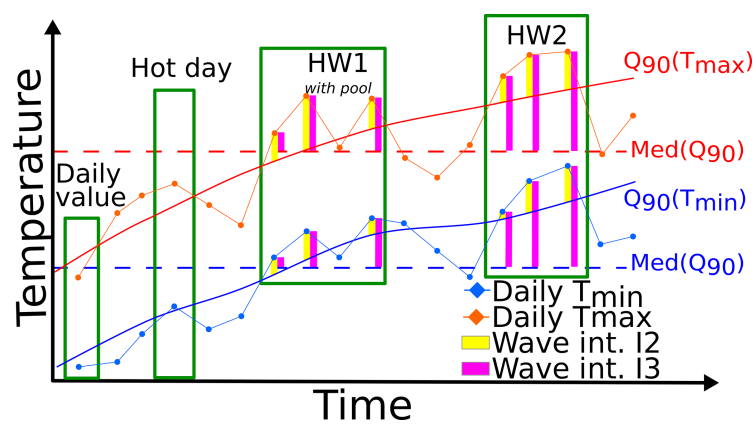

Figure 1. Schema of the detection method and the calculation of the intensities of heat waves, based on temperature anomalies of a calendar day threshold: Q90 $\left(T_{\max }\right)$ and Q90 $\left(T_{\min }\right)$ (I2 calculation), or based on the constant climatological threshold defined by the median of the daily quantiles: Med (Q90 $\left.\left(T_{\max }\right)\right)$ and Med $(\mathrm{Q} 90$ $\left.\left(T_{\min }\right)\right)$ (I3 calculation).

recommendation of WMO (2015) for health impacts, we define a heat (cold) wave as an event of at least 3 consecutive hot (cold) days (i.e. when simultaneously $T_{\min }$ and $T_{\max }$ exceed the quantile thresholds). A pool is also introduced when two events are separated by 1 day. Note that periods in between two waves are not taken into account in the wave duration and in the wave intensity. Figure 1 illustrates the method used to detect heat waves in this study.

The European mean distribution of these cases is presented in Tables 1 and 2 using the LisFlood dataset, but the results are very similar with the two other datasets (not shown). In the first column of both Tables 1 and 2 the number of hot (cold) days (above or under the quantile thresholds) are indicated. Theoretically these values should be constant and equal to $10 \%$ of the total length of the samplings. Nevertheless, due to undefined values and values equal to the thresholds, there are some differences. These tables demonstrate also the impact of using the intersection of $T_{\min }$ and $T_{\max }$ above (below) the thresholds. With respect to heat waves (Table 1), for example, in about 150 out of 376 days (i.e. $40 \%$ ) the $T_{\min }$ above the thresholds occurred simultaneously (i.e. the same day) with $T_{\max }$ above the threshold (Table 1, first column). Also, there is a significantly higher persistence of $T_{\max }$ than $T_{\min }$. For instance, using $T_{\max }$ only, $70 \%$ of the hot days (269 out of the 382) are detected as being part of a heat wave, whereas using $T_{\min }$ only, the ratio is about $60 \%$ (i.e. 226 out of 376). Using both $T_{\max }$ and $T_{\min }$, on average 81.3 days ( $54 \%$ of the hot days) are detected as being part of a heat wave (Table 1, second column). Finally, the mean occurrences of heat waves are indicated in the last column. The use of the two temperatures tends to reduce drastically the number of events (from 44 or 51 to 16.9 on average during the period) but also their durations (5.11 or 5.3 days to 4.8 ). The continental regions appear less affected by this reduction than coastal regions (not shown). Analogously, Table 2 shows the same data for cold waves. 
Table 1. Spatial mean (and standard deviation in parentheses) of total number of days detected as hot days (larger than quantile 0.9 , first column), over the entire period ( 21 years) of analysis, spatial mean of total days detected during heat waves (HW, with persistence longer than 3 days, second column) during the same period and spatial mean of total number of HW during the 21 years (third column) using only $T_{\min }$ (first row), only $T_{\max }$ (second row) and the intersection of the two variables ( $T_{\text {int }}$, third row).

\begin{tabular}{lrrr}
\hline & Hot days & Days in HW & Number of HW \\
\hline$T_{\min }$ & $376(17.9)$ & $226(31.8)$ & $44.2(5.1)$ \\
$T_{\max }$ & $382(10.7)$ & $269(31.0)$ & $51(4.9)$ \\
$T_{\text {int }}$ & $150(36.3)$ & $81.3(33.9)$ & $16.9(6.1)$ \\
\hline
\end{tabular}

Table 2. Same as Table 1 for the cold days and cold waves (CW).

\begin{tabular}{lcrr}
\hline & Cold days & Days in CW & Number of CW \\
\hline$T_{\min }$ & $380(20.8)$ & $272(30.5)$ & $50(5.3)$ \\
$T_{\max }$ & $380(14.8)$ & $282(27.4)$ & $50.3(4.3)$ \\
$T_{\text {int }}$ & $196(48.2)$ & $128(42.7)$ & $25.2(7.6)$ \\
\hline
\end{tabular}

Once a wave is detected, two main characteristics are derived: the duration (in days) and the intensity. To take into account different characteristics and to assess the sensitivity of the methods, the latter is calculated by three different methods. The first one is based on the sum of the quantiles above (or under) the threshold during the detected wave:

$$
\begin{aligned}
\mathrm{I}(n)= & \sum_{i=1}^{N} \beta \frac{\left[Q_{t_{x_{i, w}}}-\text { Thres }+Q_{t_{n_{i, w}}}-\text { Thres }\right]}{2} \\
& \left\{\begin{array}{l}
\beta=1 \text { for heat waves } \\
\beta=-1 \text { for cold waves. }
\end{array}\right.
\end{aligned}
$$

Here I1 is the intensity of the wave having a duration equal to $N$ days (except the pool days), $Q_{t_{n}}$ and $Q_{t_{x}}$ are the daily quantile of $T_{\min }$ and $T_{\max }$ at grid point $w$ and Thres, the quantile thresholds (i.e. 0.9 and 0.1 for heat and cold days respectively). The purpose of dividing this intensity by 2 is to create an intensity comparable to the intensities calculated with $T_{\min }$ and $T_{\max }$ only. The second method is similar to the first but the quantile differences are replaced by the temperature anomalies with respect to the climatological daily thresholds. This method is defined as follows:

$$
\begin{aligned}
\mathrm{I} 2(n)= & \sum_{i=1}^{N} \beta \frac{\left[T_{x_{i, w}}-Q_{T_{x}}+T_{n_{i, w}}-Q_{T_{n}}\right]}{2} \\
& \left\{\begin{array}{l}
\beta=1 \text { for heat waves } \\
\beta=-1 \text { for cold waves. }
\end{array}\right.
\end{aligned}
$$

Here $Q_{T_{x}}$ and $Q_{T_{n}}$ represent the calendar daily thresholds of $T_{\min }$ and $T_{\max }$, i.e. the temperatures for the quantiles $0.9(0.1)$ for the heat (cold respectively) waves. This method allows quantifying intensities with respect to the seasonal cycle and reflects an anomaly but not necessarily extreme values of absolute temperatures. This calculation is motivated, for example, by agricultural applications, where the crop yields can be sensitive to strong anomalies during the transitional seasons (Porter and Semenov, 2005). The last method is also based on temperature anomalies but uses a constant threshold:

$$
\begin{aligned}
& \mathrm{I} 3(n)=\sum_{i=1}^{N} \beta\left[\frac{\left[T_{x_{i, w}}-T_{x_{\mathrm{med}}\left(Q_{T_{x}}\right)}\right]}{2 \times \sigma_{T_{x}}}+\frac{\left[T_{n_{i, w}}-T_{n_{\operatorname{med}}\left(Q_{T_{n}}\right)}\right]}{2 \times \sigma_{T_{n}}}\right] \\
& \left\{\begin{array}{l}
\beta=1 \text { for heat waves } \\
\beta=-1 \text { for cold waves. }
\end{array}\right.
\end{aligned}
$$

Here $T_{x_{\operatorname{med}\left(Q_{T_{x}}\right)}}$ and $T_{n_{\operatorname{med}\left(Q_{T_{n}}\right)}}$ represent the constant temperature of the median of all calendar daily quantiles of 0.9 (heat waves) and 0.1 (cold waves) of $T_{\max }$ and $T_{\min }$. The $\sigma_{T_{x}}$ and $\sigma_{T_{n}}$ represent the climatological yearly variance of $T_{\max }$ and $T_{\min }$. This method is intended to increase the intensities of heat or cold waves that occur close to the maximum or minimum of the seasonal cycle. Based on this calculation, the strongest intensities are generally associated with the warmest or coldest absolute temperatures. The division by the variance of the seasonal cycle is justified in order to reduce the intensity of the waves that occur over a region with strong seasonal cycle, where the variability of temperature is well known to be significant. The latter method is conceptually close to the one proposed by Russo et al. (2015) and, due to its sensitivity to the absolute temperatures, might be more suitable to assess the potential impacts on human health. Figure 1 illustrates the heat wave detection and the calculation of the two last methodologies. The different intensities provided by these three methods, which use the same detection method, are discussed in the results section.

\section{Results}

\subsection{Comparison of the datasets}

In order to compare the observations and quantify the uncertainties of the results, different datasets, provided by observations and reanalysis, are used. First, the temporal correlations between different pairs of the daily quantiles are shown in Fig. 2. We notice that the correlation of the quantiles of $T_{\min }$ and $T_{\max }$ from ERAI, EOBS and LisFlood datasets are quite in agreement (the spatial mean correlation is about 0.89). Note that due to the fact that the quantiles are used, the seasonal cycle is removed, showing the quality of this agreement. The scores are generally better for $T_{\max }$ than $T_{\min }$. This can be explained by the larger spatial homogeneity of $T_{\max }$ than $T_{\min }$ and the differences in the $T_{\min }$ definition amongst National Weather Services. Indeed, over certain countries, $T_{\min }$ is measured during night time between 18:00 and 06:00 LT the following day, elsewhere from 00:00 to 24:00 LT or from 06:00 LT on day $d$ to 06:00 LT on day 


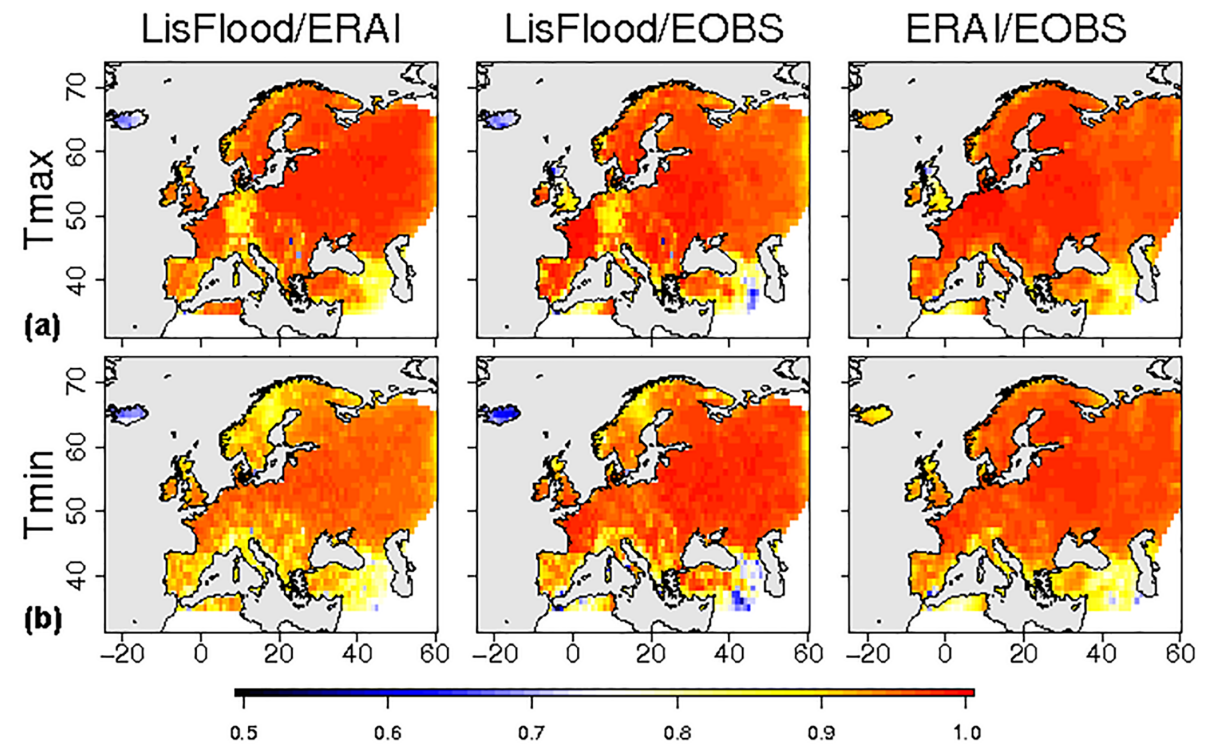

Figure 2. Temporal correlation of the temperature quantiles of $T_{\min }(\mathbf{a})$, and $T_{\max }(\mathbf{b})$ provided by ERAI, EOBS and LisFlood datasets from 1995 to 2015. The datasets compared are indicated on the top of each column.

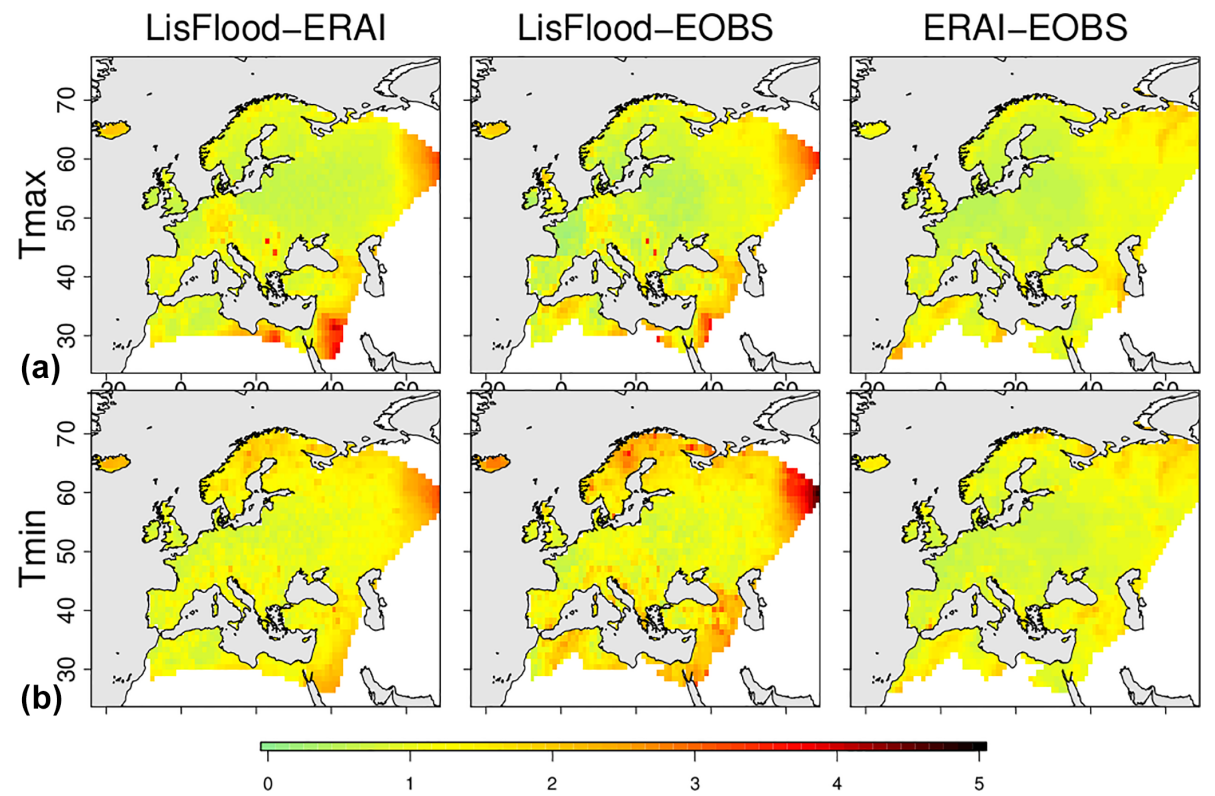

Figure 3. Mean absolute error of temperature (in K) between the three datasets, calculated from 1995 to 2015 for $T_{\min }$ (a) and $T_{\max }$ (b). The datasets compared are indicated on the top of each column.

$d+1$, which can result in a delay of 1 day. In the EOBS data description, and in van den Besselaar et al. (2011), this point and the uncertainties associated are deeply analysed. Due to the coarser resolution and the use of only four recorded values per day to calculate $T_{\min }$ and $T_{\max }$, ERAI is associated with a hot bias of $T_{\min }$ and a cold bias of $T_{\max }$ in relation to both LisFlood and EOBS datasets (not shown). The yearly mean absolute error of $T_{\min }$ and $T_{\max }$ (MAE, Fig. 3, very close to the root mean square difference) remains, however, relatively low $\left(<1.5^{\circ}\right)$ except at the borders of the domain, confirming the good agreement especially between EOBS and ERAI. Note that the LisFlood dataset is slightly less correlated to the others over Scandinavia, Germany and the northeasternmost part of the domain - probably due to the definition of $T_{\min }$ and $T_{\max }$ for each country, delay in the GTS communications and the density of the stations (the E-OBS network over Germany and Scandinavia is quite dense). 


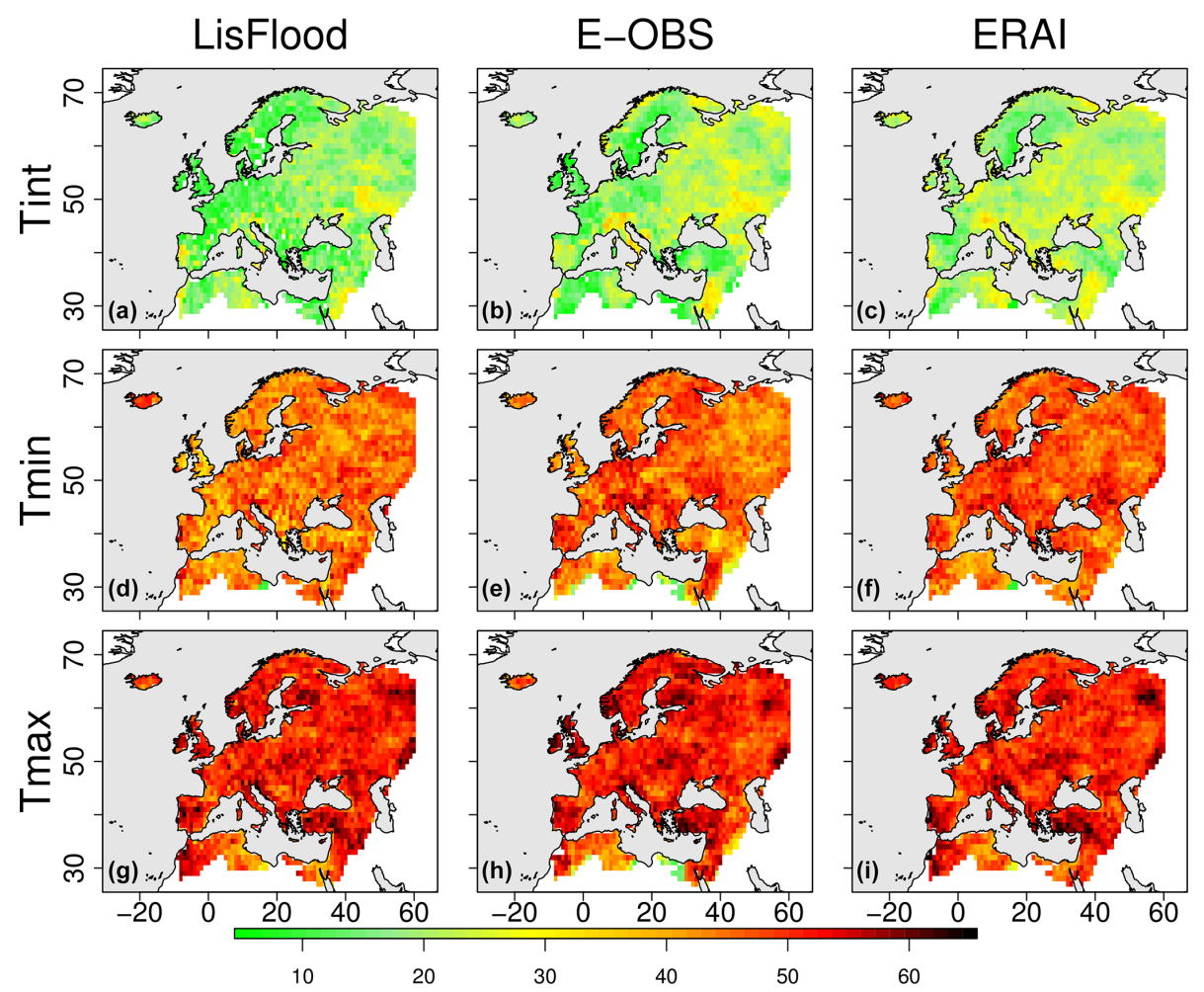

Figure 4. Number of occurrences of heat waves in Europe from 1995 to 2015 using the intersection of both $T_{\min }$ and $T_{\max }$ (Tint, a-c), only $T_{\min }(\mathbf{d}-\mathbf{f})$, and only $T_{\max }(\mathbf{g}-\mathbf{i})$ with LisFlood $(\mathbf{a}, \mathbf{d}, \mathbf{g})$, E-OBS $(\mathbf{b}, \mathbf{e}, \mathbf{h})$ and ERAI $(\mathbf{c}, \mathbf{f}, \mathbf{i})$ datasets.

\subsection{Climatology}

\subsubsection{Variability in the occurrence of the waves}

The total occurrences of heat and cold waves during the 21 years are calculated using the definitions presented in Sect. 2. This is performed independently for the three datasets to provide information on the robustness of the results. As shown in Tables 1 and 2, cold waves are more frequent than heat waves for the three datasets, especially in the eastern part of Europe (Figs. 4 and 5, first row). The independent use of $T_{\min }$ and $T_{\max }$ to detect, respectively, heat and cold waves reveals more homogeneous spatial patterns and a similar rate of occurrence across the three datasets, but about 50 to $60 \%$ more than for the intersection of $T_{\min }$ and $T_{\max }$ (Figs. 4 and 5, second and third row). The detection of the heat waves using $T_{\min }$ only generates fewer events. These results highlight two main characteristics: (1) the lower persistence of $T_{\min }$ with strong anomalies could partially explain the difference between the occurrence of heat and cold waves; (2) the increase of the occurrence in the continental regions is mainly explained by an increase of the simultaneous anomalies in $T_{\min }$ and $T_{\max }$ rather than an increase of the two occurrences. These two characteristics may be explained by the synoptical situations during cold waves and the fact that there are more frequent meteorological blocking conditions in winter than in summer (Tibaldi et al., 1994;
Doblas-Reyes et al., 2002). Several recent studies (Tomczyk and Bednorz, 2016; Sousa et al., 2017) have emphasized the important role of persistent and intense blocking and associated anticyclones in producing heat or cold waves. The origins of the extreme blocking situations are still not well understood and could be related to the development of a largescale Rossby train (Trenberth and Fasullo, 2012). Schubert et al. (2014), who identified western Russia as the leading mode of surface temperature and precipitation covariability, have highlighted the potential feedback of the soil moisture in enhancing the intensities of the heat waves over this region (Fisher et al., 2007; Mueller and Seneviratne, 2013; Miralles et al., 2014; Whan et al., 2015).

The main difference between the datasets is the higher occurrence of both heat and cold waves for ERAI than for the other datasets. This could be an effect of the coarser resolution in time and space of the reanalysis data compared to the ground observations, which tends to smooth the temporal evolution of the temperature anomalies and so of the quantiles. Due to that lower temporal variability, the chance to get long-term anomalies is increased when using ERAI as compared to the other datasets.

The distribution of the wave durations is needed to complete the picture of the total number of occurrences of all individual waves. Figure 6 displays the spatial variability of the last quartile of the wave durations recorded for each 

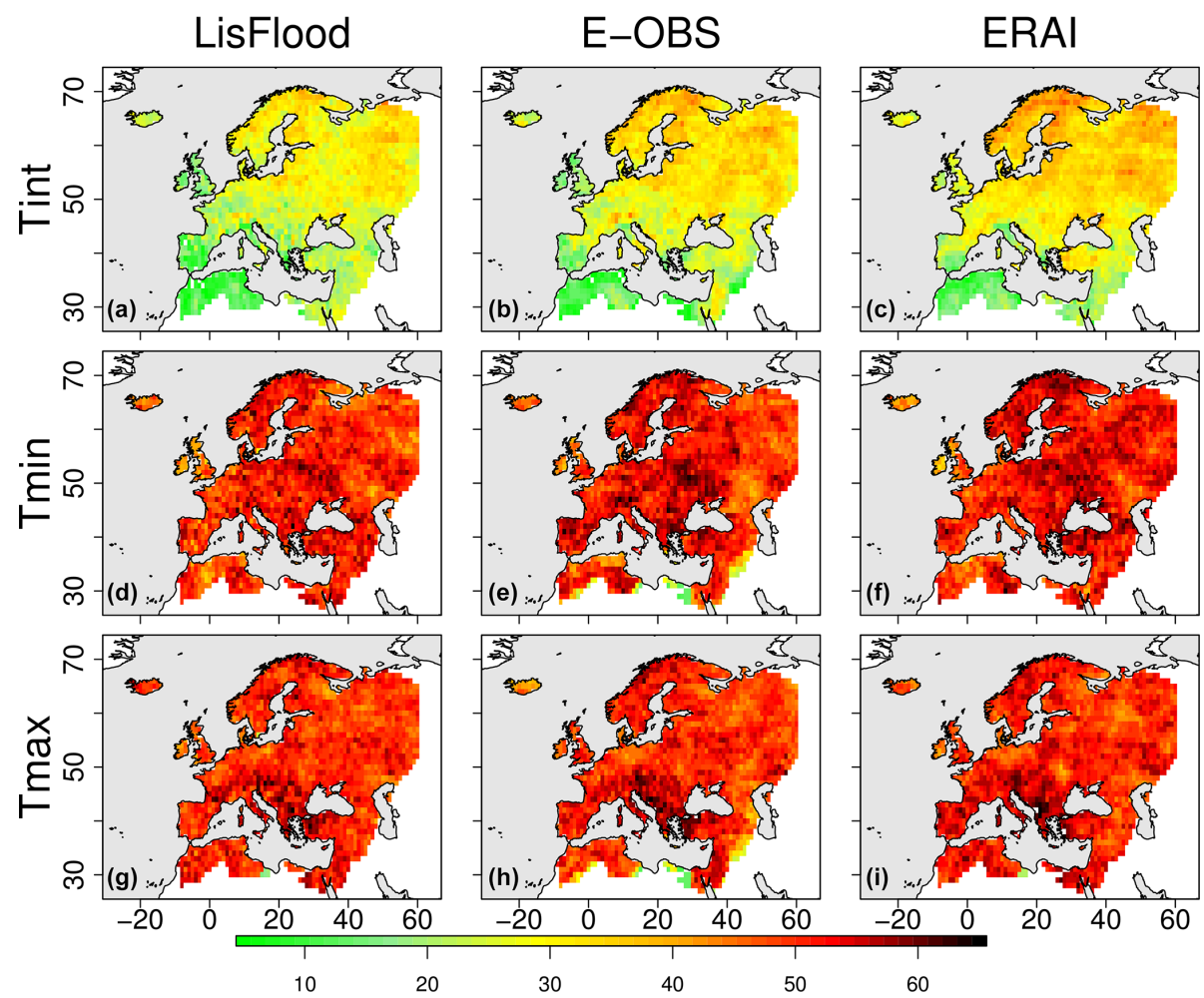

Figure 5. Number of occurrences of cold waves in Europe from 1995 to 2015 using the intersection of both $T_{\min }$ and $T_{\max }$ (Tint, a-c), only $T_{\min }(\mathbf{d}-\mathbf{f})$, and only $T_{\max }(\mathbf{g}-\mathbf{i})$ with LisFlood $(\mathbf{a}, \mathbf{d}, \mathbf{g})$, E-OBS $(\mathbf{b}, \mathbf{e}, \mathbf{h})$ and ERAI $(\mathbf{c}, \mathbf{f}, \mathbf{i})$ datasets.
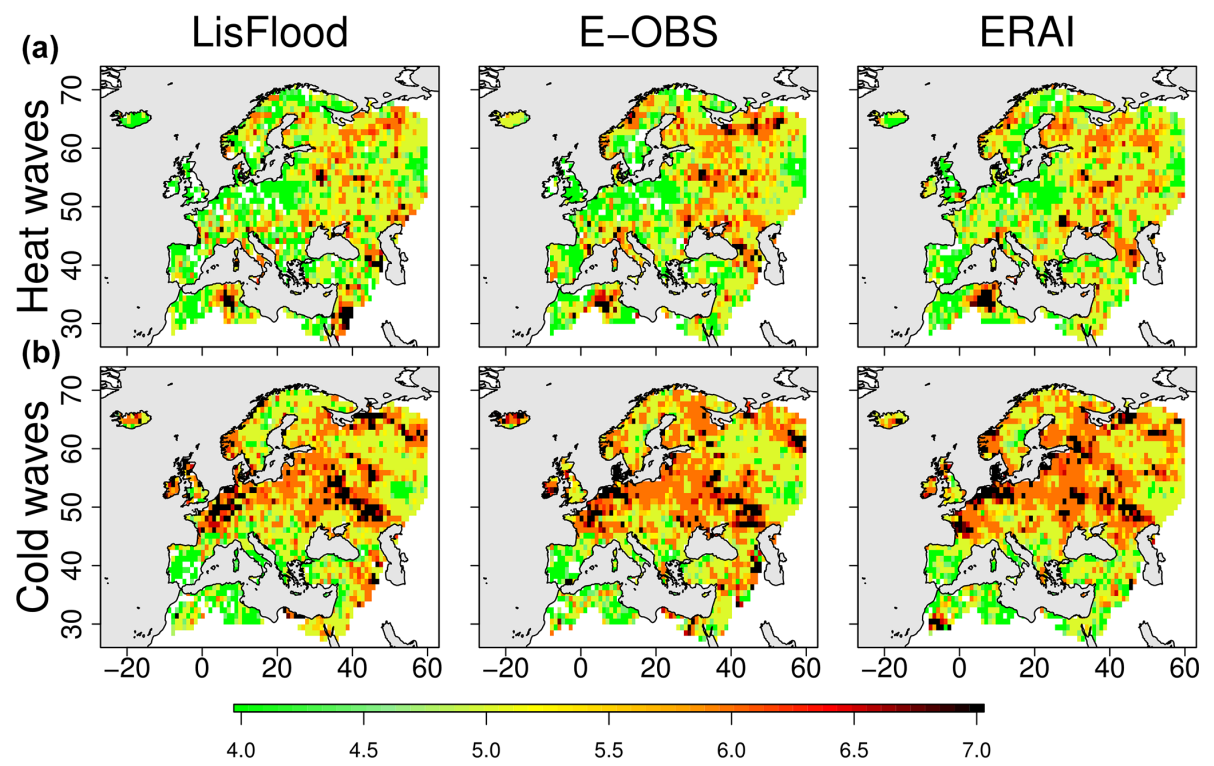

Figure 6. Last quartile of the wave durations (in days) for the heat (a) and cold (b) waves using LisFlood, E-OBS and ERAI datasets.

grid point. It appears that the difference between the durations of heat and cold waves between the three different datasets is much lower than the difference of occurrence discussed previously (Figs. 4 and 5). It is also interesting to note that, especially for cold waves, the regions where the waves are the most frequent are not the same as where they are the most persistent. Finally, it is remarkable to see many of the longest durations of the cold waves along the coasts of the North Sea and the Baltic Sea. Indeed, the climate along the coasts is generally more variable than in the continental 
Intensities derived from quantiles (I1)
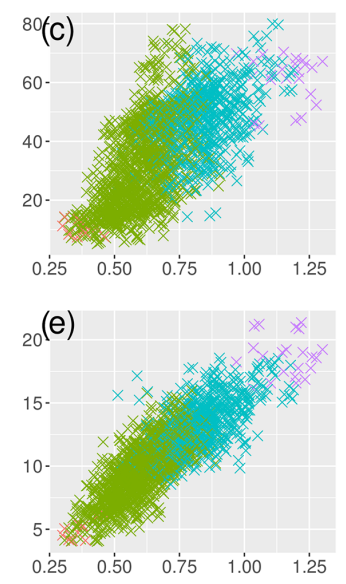
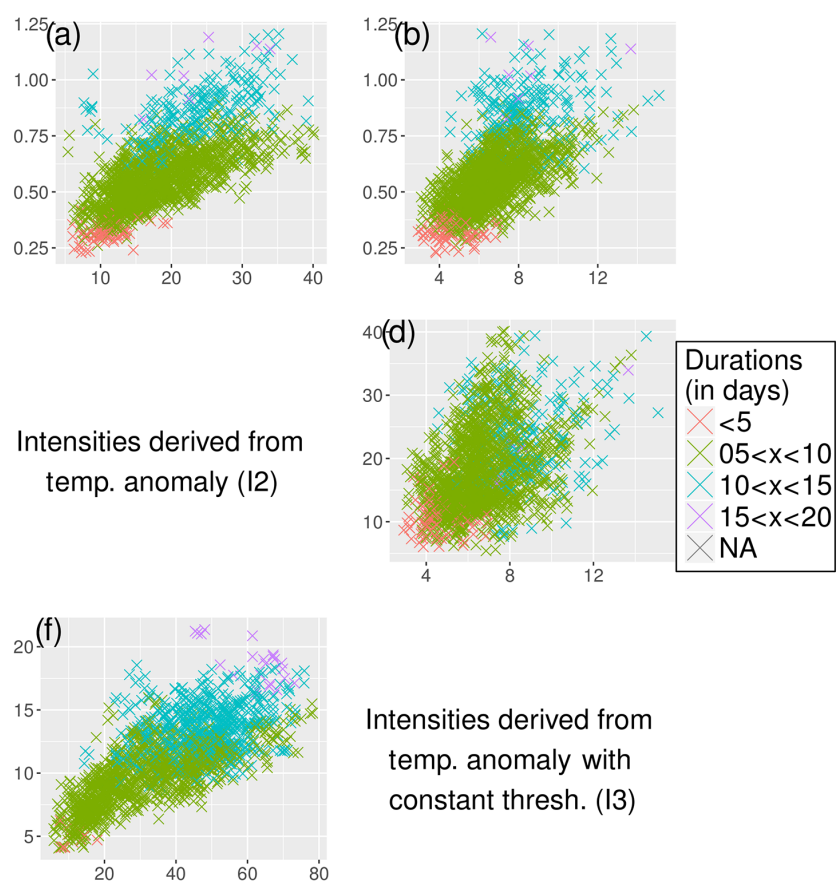

Intensities derived from

temp. anomaly with

constant thresh. (I3)

Figure 7. Matrix of scatter plots of the three intensity calculations related to quantiles, temperature anomalies and temperatures anomalies with constant thresholds (I1, I2 and I3 respectively) during heat (a, b, d) and cold (c, e, f) waves using LisFlood. The colours indicate the duration (in days) of each wave.

regions, and so the waves are expected to be shorter. According to the same calculations using only $T_{\min }$ or $T_{\max }$ (not shown), the spatial heterogeneity of the cold wave durations is much larger when $T_{\max }$ is used than when $T_{\min }$ is used and we observe a strong increase of the wave durations with $T_{\max }$ over northern Germany, Denmark, northern Poland, the Baltic Sea and southern Scandinavia. This highlights the persistence of negative anomalies of $T_{\max }$ over these regions, which could increase the chance to get longer durations with the intersection method and could explain the results in Fig. 6. In other words, the Baltic Sea stabilizes the temperature variability and therefore generates a signal with lower high-frequency modulations. When an anomaly occurs, it has a greater chance of lasting longer and so potentially induce longer heat/cold waves. This is due to our detection method of heat and cold waves that is based on the quantiles and not on absolute temperatures. The latter are generally less variable and less extreme values are detected along the coasts. In addition, the wavelet analysis (Torence and Compo, 1998) of temperature in winter and summer was also calculated to analyse the frequency variabilities of the signal. This showed that the regions with low modulations (eastern Europe in summer or northern Russia and the north of Poland in winter) are also the regions with high frequency of occurrence or with longer durations (not shown).

\subsubsection{Intensity of the heat and cold waves}

The climatology of the intensities is important in order to provide a baseline and to calibrate the wave monitored but the values of these intensities are very sensitive to the methods applied. The three methods, I1, I2 and I3 (using the quantiles, the temperature anomalies and the constant threshold of temperature, see Sect. 2.2), are compared during heat and cold waves in Fig. 7. The distributions of each scatter plot indicate the relationships by pairs in between the three methods for all the events, and the colours indicate the corresponding durations of the events. Note that Fig. 7 refers to LisFlood, but the same results are obtained for the other datasets. These panels show the strong dependence of the intensities derived from the quantiles and the durations (colour distribution more vertically distributed in Fig. $7 \mathrm{~b}$ and horizontally in Fig. 7c and e). This is especially true for the cold waves (correlations in between duration and I1 larger than 0.95). These high correlations highlight the redundancy in the information with the wave durations. Moreover, I1 is also climatologically bounded by the values recorded during the past period. For these reasons the use of the quantiles appears not suitable to assess the heat and cold wave intensities. The methods derived from the temperature anomaly (I2) and the constant threshold (I3) are therefore chosen. Indeed, the correlations between the wave durations and I 2 and with $\mathrm{I} 3$ are much lower and not significant (on average 0.72 and 0.59 ), showing the potential additional information provided by $\mathrm{I} 2$ and 

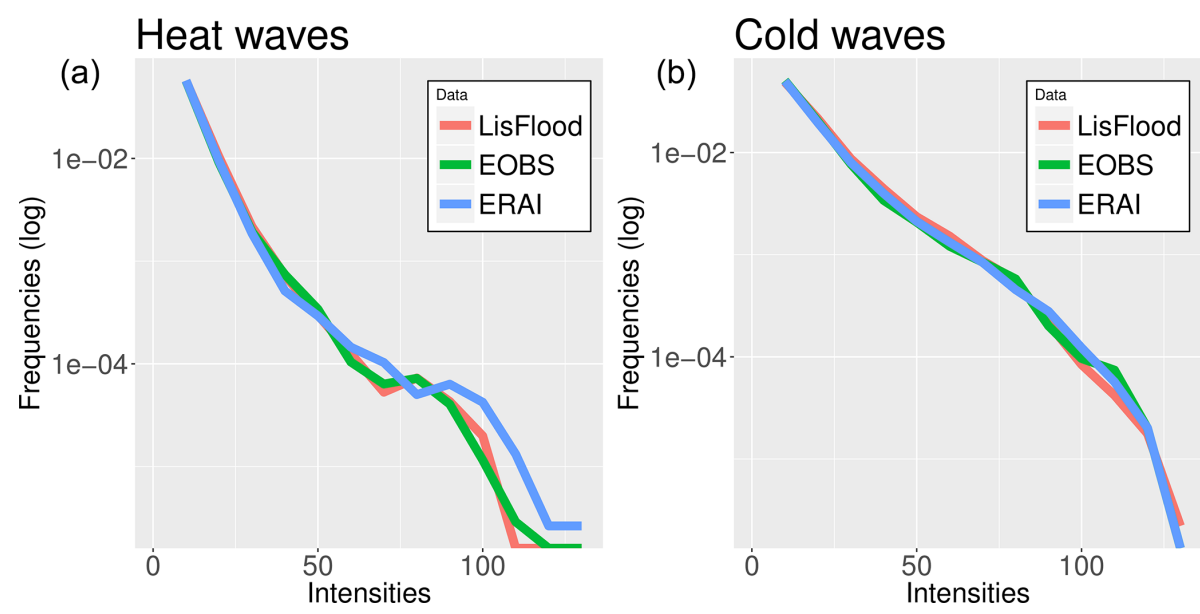

Figure 8. Histograms of heat (a) and cold (b) wave intensities defined as temperature anomalies (I2) for the three datasets. Note that the frequency axes are on a log scale.

I3. Moreover, these values are not bounded by the historical values and so they will be able to better distinguish the most severe cases. According to the scatter plots in Fig. $7 \mathrm{~d}$ (for the heat waves) and Fig. $7 \mathrm{f}$ (for the cold waves), these methods appear quite independent at the European scale. Nevertheless, the analysis of the correlations at the grip point level reveals a large spatial variability (not shown). For instance, the correlations of I 2 and I3 go up to 0.95 over France and western Russia, explained by heat (cold) waves that occurred during the warmest (coldest) months, and go down to 0.5 over central and northern Europe.

Except for the strongest events, there is an overall good agreement of the datasets in terms of the probability distribution functions of the intensities of heat and cold waves. Figure 8 displays the distribution of intensities defined by the method of the temperature anomalies (I2) and shows no significant differences for intensities lower than 60 . This figure also confirms our finding of the higher occurrence of cold waves than heat waves especially with intensities larger than 25. In the tails of the distribution (especially for the heat waves larger than 90), the differences are associated with a very low number of cases. The spatial variability of these I2-based intensities in the last 21 years was assessed by the strongest cold and heat waves recorded over each grid point (Fig. 9). The two strongest heat waves that occurred in Europe can be clearly identified, namely the one that occurred in Russia in 2010 and the one in France in 2003. For these two events, the intensities are slightly stronger and longer using ERAI (not shown). For the cold waves, the intensities are stronger than the heat waves. The most intense events occurred over the continental regions (central Europe and the south of Russia). The three datasets are in good agreement for the intensities and the spatial variabilities. It is interesting to highlight that these intensities are not well correlated to the occurrence - i.e. a region with more cases does not necessarily record the most extreme events (Figs. 4 and 5). We note that the relatively short period of study (21 years) could generate some artefacts over regions that recorded extraordinary events (e.g. Russia).

To assess meteorological uncertainties, Fig. 10 displays the same distributions but for intensities calculated using constant thresholds (I3). Although the scales are different, the spatial distribution of I2 and I 3 for the strongest heat waves is quite similar. The patterns are strongly influenced by the two heat waves in 2003 and 2010. In contrast, the distribution of the strongest cold waves changes drastically. While the intensities over Russia are reduced, we note a relative increase of the intensities over western Europe, especially in north Germany, the Netherlands, and in central Europe. As discussed previously, this could be explained by events that occurred during the transitional months (intense I2 but not I3) or close to the maximum (or minimum) seasonal temperature (intense I3). The spatial distribution is also influenced by the normalization according to the amplitude of the seasonal cycle, which is larger in continental regions (not shown). Even if the results display significant differences according to the methods and the regions, it is important to note that the three datasets are still in good agreement.

\subsection{Return periods}

As the purpose of this study is to provide a methodology that is usable for a monitoring system that must be robust and understandable for users and decision makers, the information should also be provided in terms of return periods. This product will quantify, at the monthly timescale, the intensity of the cold or heat waves that have occurred. To build this indicator, all the days defined as cold or heat waves are summed for different accumulation periods (from monthly to seasonally, see Table 3). Monthly values characterize either one specific event as defined previously or several consecutive cases. As indicated by WMO (2015), intense or repetitive 

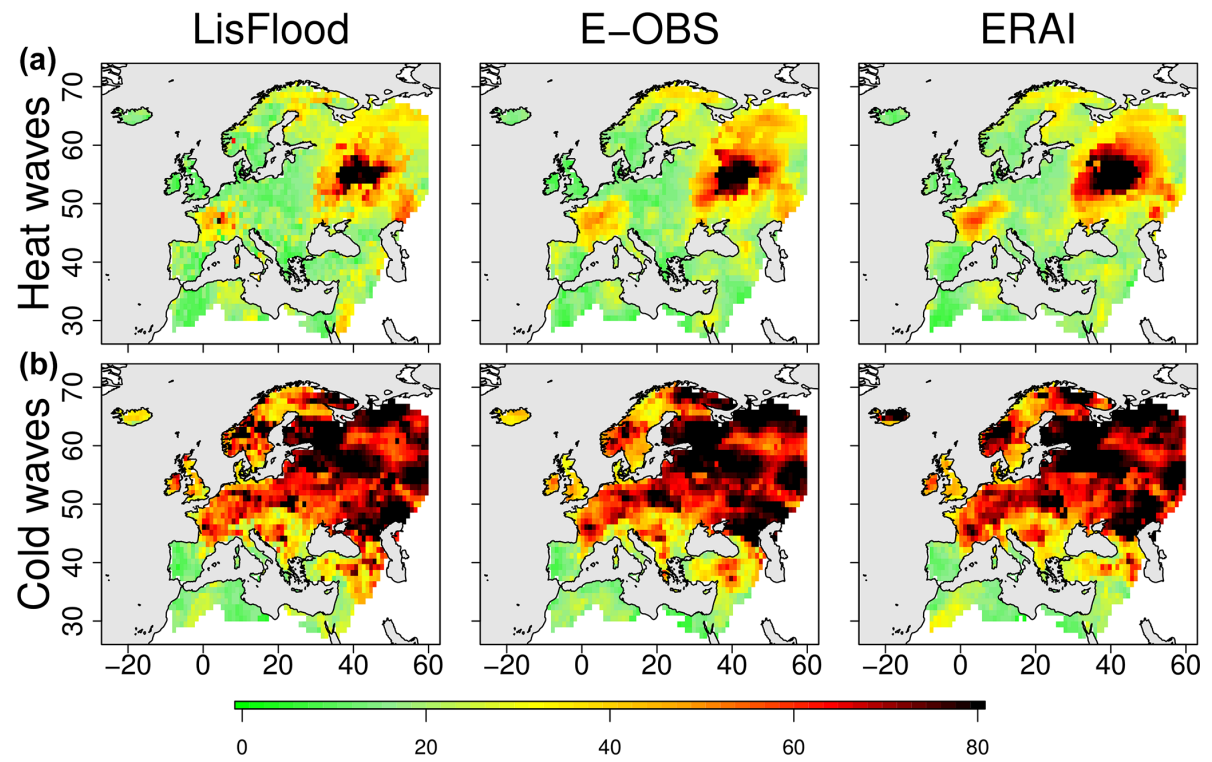

Figure 9. Spatial distribution of the strongest heat (a) and cold (b) waves intensities, defined as temperature anomalies (I2), using LisFlood, E-OBS and ERAI datasets.

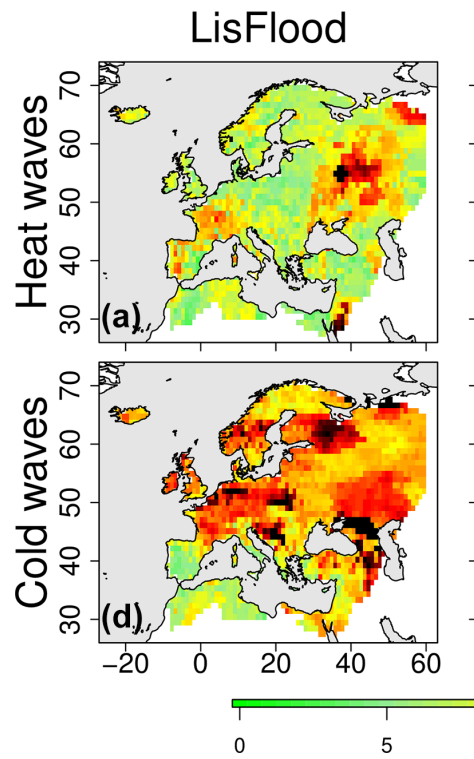

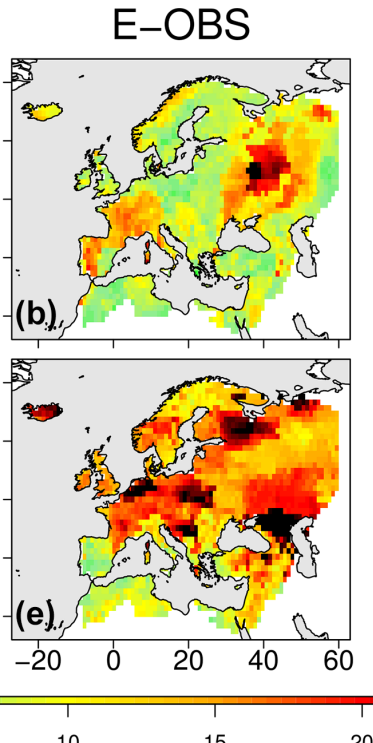

15
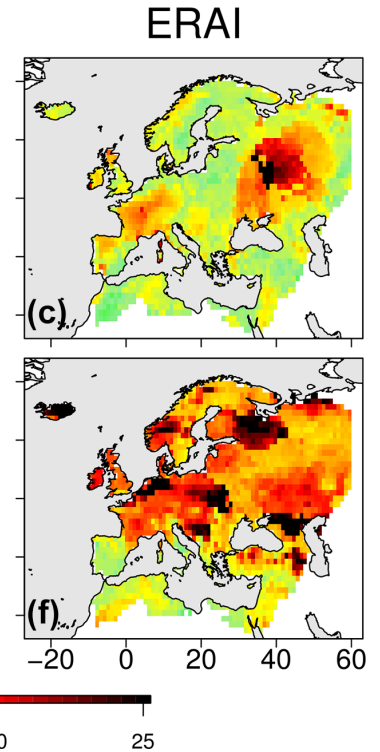

Figure 10. Same as Fig. 9 using the intensity based on the constant threshold (I3) for heat (a-c) and cold (d-f) waves, and based on LisFlood (a, d), E-OBS (b, e) and ERAI (c, f).

extreme waves may have strong impacts on human health and so should be assessed. Once these monthly values are calculated for each grid point, the return period is estimated. Problems when dealing with extremes are linked to erroneous values and the sampling. To partially address these issues, we have compared different datasets, and different theoretical distributions have been fitted and tested. This is done at both grid-point and regional level. Other distributions have been applied in the literature - such as the gamma (Meehl et al., 2000) or the Weibull distribution (Cueto et al., 2010).
According to the Pearson goodness-of-fit statistic, and the deviance statistic on the entire distribution, the gamma distribution is the most suitable (not shown). By using this theoretical distribution, the return periods can be extrapolated beyond the 21-year period. Once the parameters of the gamma distribution are estimated for monthly, bimonthly and seasonal timescales (see Table 3), return periods are calculated for both the cold and heat waves. According to significance tests employed to guarantee the robustness of the distribution, uncertainties exist for return periods larger than the du- 
Table 3. Accumulation periods used to calculate the return period of wave intensities. The type of waves (cold or heat) is indicated in the second row and the accumulation period of the sum of intensities is indicated in the last row (1 for 1-month accumulation period, 2 for 2-month accumulation period and $\mathrm{S}$ for Season, i.e. 6-month accumulation period).

\begin{tabular}{lrrrrrrrrrrrr}
\hline Months & Jan & Feb & Mar & Apr & May & Jun & Jul & Aug & Sep & Oct & Nov & Dec \\
\hline Type & Cold & Cold & Cold & Heat & Heat & Heat & Heat & Heat & Heat & Cold & Cold & Cold \\
Duration & 1,2 & 1,2 & $1,2, \mathrm{~S}$ & 1 & 1,2 & 1,2 & 1,2 & 1,2 & $1,2, \mathrm{~S}$ & 1 & 1,2 & 1,2 \\
\hline
\end{tabular}

(a) Intensities 12

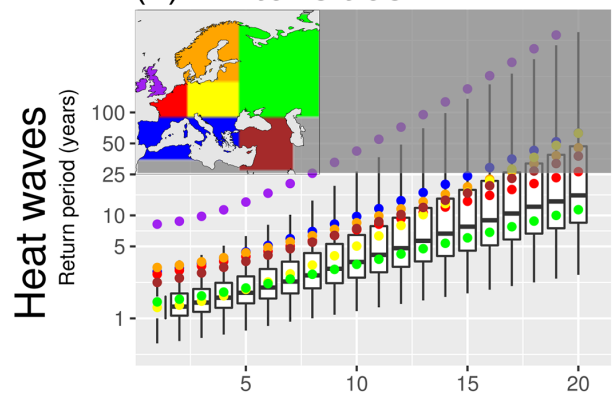

(c)

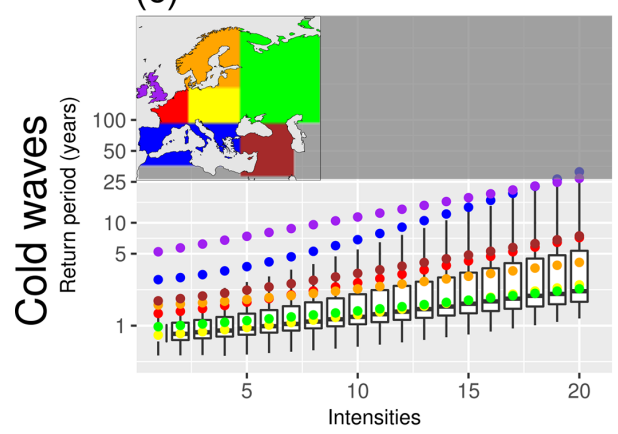

(b) Intensities I3

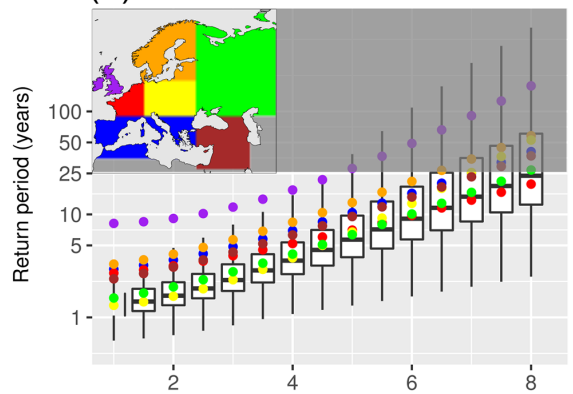

(d)

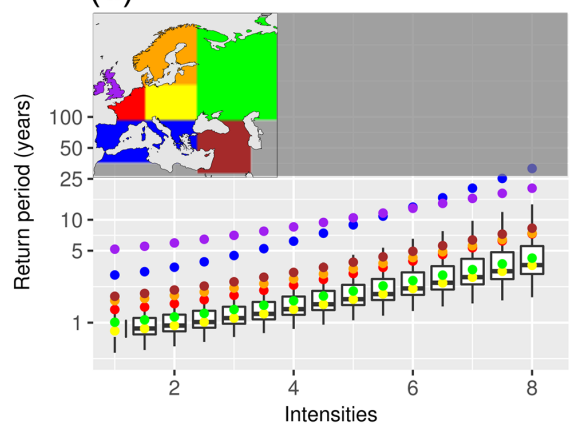

Figure 11. Return periods of monthly intensities of heat (a, b) and cold (c, d) waves for two intensities (I2, a, c, and I3, b, d). Boxes assess the spatial variability for the grid points. Coloured dots indicate the return period calculated over the regions defined in the small panels.

ration of the observed sampling. For these reasons, return periods longer than 25 years are reported with grey shadows and, in addition, the $x$ axis in Fig. 11 is limited in order to have at least $50 \%$ of grid points not exceeding a 25 -year return period. Under these conditions, all the events that have return periods larger than the duration of the sampling will not be distinguished and all of them will be considered as the "most dangerous". The return period results were produced using the LisFlood dataset, which has been validated in the previous section, but similar results were obtained with the two other datasets.

The boxplots (Fig. 11) show the relationships between intensities and return periods over each grid point in Europe. According to the size of the interquartiles, a large spatial variability emerges over the domain. For instance, heat waves with intensities of 20 (8) using I2 (I3) have interquartiles of return period that span from 7 to 50 years ( 15 to 90 years respectively). The use of other datasets provides similar results. Nevertheless, ERAI has less spatial variability (lower spread of the boxes), and lower return periods associated with the larger wave intensities (not shown).

The spatial variabilities are then analysed in more detail with a regional classification. This classification is a simplification of the one shown in the EEA report (2016) that takes into account the climatology of the regions (Continental, Mediterranean, Oceanic, Scandinavian, small panels in Fig. 11). Over these regions, the return periods are assessed and compared (coloured dots in Fig. 11). Even if the results for the two intensities (left and right panels) cannot be compared directly, it is interesting to compare the ranking of the regions according to the return periods. For heat waves, the British Isles stand out by using the two intensities. The few intense heat waves recorded generate return periods in the outliers of the box distribution in Europe. In contrast, the Russian region records the lowest return periods for similar intensities using I2, showing the large hazard of these heat waves in this region. Nevertheless, the use of the I3 calculation (more sensitive to waves that occurred during the heart of the season) shows a different distribution, with more cases 

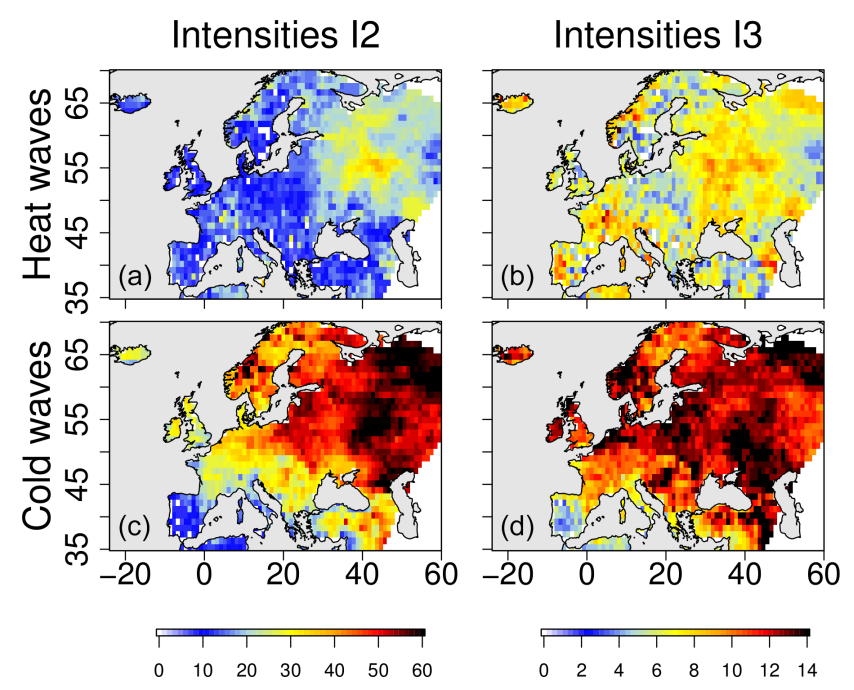

Figure 12. Intensity of the heat $(\mathbf{a}, \mathbf{b})$ and cold $(\mathbf{c}, \mathbf{d})$ waves defined with the temperature anomalies (I2, a, c), or with constant thresholds (I3, b, d) with a 10-year return period using LisFlood dataset.

over central Europe for return periods lower than 5 years (in yellow) and the northwest European region (red) for the most intense heat waves. For the cold waves, the British Isles and the Mediterranean regions are the least affected in the two intensity calculations, whereas the continental parts of Europe (Russia and central Europe) are associated with more regular intense cold waves.

In Fig. 12, both I 2 and I3 intensities of the heat and cold waves with a return period of 10 years are plotted. As these values depend on the observed waves in the analysed period, a hot spot over western Russia appears (Fig. 12a, c). In that region in the last 21 years, waves were more frequent (Figs. 4 and 5) and more intense (Fig. 9). The results with I3 show different behaviours (Fig. 12b, d). This is due to the different location of the most intense waves (Fig. 10). The potential impacts of these heat and cold waves will be calculated as a function of the absolute intensities and the return periods. However, we can expect that identical wave intensities over two different regions, and therefore with two different return periods, may have different impacts. For example, the absolute value of the heat wave intensity recorded in August 2003 over France using I3 does not give extreme values with respect to the intensities recorded in continental regions. Nevertheless, the equivalent return value over France is larger than 50 years (not shown), in agreement with Barriopedro et al. (2011) and Trigo et al. (2005), which suggests the potential strong associated risk.

Given the 21-year period used in this study, the return period can identify the most extreme situations. The same information will also be available for the 2-month and seasonal timescales (not shown).

\section{Discussion}

The purpose of this study was to develop a system to monitor potential high-impact climate extreme events. Defining the intensity of an extreme event is important since it provides the hazard component to be related to human or economic impacts. Many studies have already dealt with this issue, but no consensus has been reached so far for heat and cold waves. Large local differences usually prevent the use of a single definition for impact-oriented global studies. One option is to apply a constant threshold such as 35 or $40^{\circ}$ for heat waves and -10 or $-20^{\circ}$ for cold waves across an entire continent, as these definitions are understandable and easy to communicate. Nevertheless, such a choice can be questionable. For example, the heat wave in France in 2003 was associated with absolute temperatures close to $40^{\circ}$; which are relatively close to the climatology for southern Spain. The impacts, therefore are not just temperature dependent, but they vary according to the geographical location (and thus the local climate), the societal exposure and vulnerability. For all these reasons, it is difficult to identify the most robust indicator. The ones chosen in this study are based on the rarity of the events. The implicit assumption made is that rarity is associated with a lack of specific adaptation and thus with higher risk.

\section{Summary and conclusions}

In this study, we assessed the feasibility of monitoring heat and cold waves by using a method based on the persistence of the exceedance of quantiles of daily minimum and maximum temperatures at grid point level. In the first step, three methods to detect and quantify the intensities of heat and cold waves were assessed. The use of $T_{\min }, T_{\max }$ and of both values was investigated. This demonstrated how the combined use of the two daily temperatures reduces the frequency of the extremes. To make the analysis more robust, three datasets were compared, two derived from station data (LisFlood and EOBS) and one from reanalysis data (ERAI). The two observational datasets showed only minor differences in heat and cold waves occurrences and intensities. This is probably due to the good agreement in representing both $T_{\min }$ and $T_{\max }$. Using ERAI some differences appeared, mainly due to the coarser resolution of the original grid and the use of only four values per day to define $T_{\min }$ and $T_{\max }$. In this case, the persistence and the spatial correlation increased, generating less spatial distinction and more intense waves with respect to the other two datasets. However, the main results are in overall agreement for all three datasets and show a larger hazard for heat and cold waves in the continental part of Europe. Return periods were also estimated, and this information will be used operationally in the EDO system to provide robust and comprehensible products for decision makers and users. 
In perspective, these datasets and results should be compared to the ones derived from forecast products in order to be able to provide a comprehensive and seamless tool for monitoring and forecasting heat and cold waves in Europe.

Data availability. All the data on detection and intensities of the heat and cold waves in Europe are available on demand or on the European Drought Observatory web page (http://edo.jrc.ec.europa. $\mathrm{eu} /)$.

Competing interests. The authors declare that they have no conflict of interest.

Acknowledgements. The authors would like to thank the two anonymous reviewers for their helpful comments.

Edited by: Vassiliki Kotroni

Reviewed by: two anonymous referees

\section{References}

Barriopedro, D., Fischer, E. M., Luterbacher, J., Trigo, R. M., and García-Herrera, R.: The hot summer of 2010: redrawing the temperature record map of Europe, Science, 332, 220-224, 2011.

Budd, G. M.: The wet-bulb globe temperature: its history and limitations, J. Sci. Medicine in Sport, 11, 20-32, 2009.

Cueto, R. G., Martinez, A. T., and Ostos, E. J.: Heat waves and heat days in an arid city in the northwest of Mexico: current trends and in climate change scenarios, Int. J. Biometeorol., 54, 335$345,2010$.

de'Donato, F. K., Leone, M., Noce, D., Davoli, M., and Michelozzi P.: The Impact of the February 2012 Cold Spell on Health in Italy Using Surveillance Data, PLoS ONE, 8, e61720, https://doi.org/10.1371/journal.pone.0061720, 2013.

Dee, D. P., Uppala, S. M., Simmons, A. J., Berrisford, P., Poli, P., Kobayashi, S., and Bechtold, P.: The ERA-Interim reanalysis: Configuration and performance of the data assimilation system, Q. J. Roy., Meteor. Soc., 137, 553-597, 2011.

De Roo, A. P. J., Wesseling, C. G., and Van Deursen, W. P. A.: Physically based river basin modelling within a GIS: the LISFLOOD model, Hydrol. Process., 14, 1981-1992, 2000.

Doblas-Reyes, F. J., Casado, M. J., and Pastor, M. A.: Sensitivity of the Northern Hemisphere blocking frequency to the detection index, J. Geophys. Res.-Atmospheres, 107, 4009, https://doi.org/10.1029/2000JD000290, 2002.

EEA report: Climate Change, impacts and vulnerability in Europe in 2016, an indicator-based report, EEA report (1/2017), ISSN 1977-8449, 2016.

Fischer, E. M., Seneviratne, S. I., Vidale, P. L., Lüthi, D., and Schär, C.: Soil-Atmosphere interactions during the 2003 European summer heat wave, J. Climate, 5081-5099, https://doi.org/10.1175/JCLI4288.1, 2007.
Gasparrini, A. and Armstrong, B.: The impact of heat waves on mortality, Epidemiology, 22, 68-73, https://doi.org/10.1097/EDE.0b013e3181fdcd99, 2011.

Gonzalez-Hidalgo, J. C., Peña-Angulo, D., Brunetti, M., and Cortesi, N.: Recent trend in temperature evolution in Spanish mainland (1951-2010): from warming to hiatus, Int. J. Climatol., 36, 2405-2416, 2016.

Haylock, M. R., Hofstra, N., Klein Tank, A. M. G., Klok, E. J., Jones, P. D., and New, M.: A European daily highresolution gridded data set of surface temperature and precipitation for 1950-2006, J. Geophys. Res.-Atmos., 113, D20119, https://doi.org/10.1029/2008JD010201, 2008.

Hirschi, M., Seneviratne, S. I., Alexandrov, V., Boberg, F., Boroneant, C., Christensen, O. B., Formayer, H., Orlowsky, B., and Stepanek, P.: Observational evidence for soil-moisture impact on hot extremes in southeastern Europe, Nat. Geosci., 4, 17-21, 2011.

Kharin, V. V., Zwiers, F. W., Zhang, X., and Wehner, M.: Changes in temperature and precipitation extremes in the CMIP5 ensemble, Clim. Change, 119, 345-357, 2013.

Kovats, R. S. and Kristie, L. E.: Heatwaves and public health in Europe, Eur. J. Public Health, 16, 592-599, 2006.

Kuglitsch, F. G., Toreti, A., Xoplaki, E., Della-Marta, P. M., Zerefos, C. S., Türkeş, M., and Luterbacher, J.: Heat wave changes in the eastern Mediterranean since 1960, Geophys. Res. Lett., 37, L04802, https://doi.org/10.1029/2009GL041841, 2010.

Li, P. W. and Chan, S. T.: Application of a weather stress index for alerting the public to stressful weather in Hong Kong, Meteorol. Appl., 7, 369-375, 2000.

Meehl, G. A., Karl, T., Easterling, D. R., Changnon, S., Pielke Jr., R., Changnon, D., Evans, J., Groisman, P., Knutson,T., Kunkel, K., and Mearns, L. O.: An introduction to trends in extreme weather and climate events: observations, socioeconomic impacts, terrestrial ecological impacts, and model projections, B Am. Meteorol. Soc., 81, 413-416, https://doi.org/10.1175/15200477(2000)081<0413:AITTIE>2.3.CO;2, 2000.

Miralles, D. G., Teuling, A. J., van Heerwarden, C. C., and VilàGuerau de Arellano, J.: Mega-heatwave temperatures due to combined soil desiccation and atmospheric heat accumulation, Nat. Geosci., 7, 345-348, 2014.

Mueller, B. and Seneviratne, S.: How soils send messages on heat waves, IGBP's Global Change magazine, No. 81, available at: http://www.igbp.net/news/ features/features/howsoilssendmessagesonheatwaves.5. 30566fc6142425d6c911a33.html, October 2013.

Monhart, S., Spirig, C., Bhend, J., Liniger, M. A., Bogner, K., and Schär, C.: Verification of ECMWF monthly forecasts for the use in hydrological predictions, EGU General Assembly Conference Abstracts, 18, 14122, 2016.

Montero, J. C., Mirón, I. J., Criado-Álvarez, J. J., Linares, C., and Díaz, J.: Influence of local factors in the relationship between mortality and heat waves: Castile-La Mancha (1975-2003), Sci. Total Environ., 414, 73-80, 2012.

Perkins, S. E. and L. V. Alexander: On the measurement of heat waves, J. Climate, 26, 4500-4517, 2013.

Porter, J. R. and Semenov M. A.: Crop responses to climatic variation, Philos. T. Roy. Soc. B, 360, 2021-2035, 2005.

Robine, J. M., Cheung, S. L. K., Le Roy, S., Van Oyen, H., Griffiths, C., Michel, J. P., and Herrmann, F. R.: Death toll exceeded 
70,000 in Europe during the summer of 2003, C. R. Biol., 331, 171-178, 2008

Rocklov, J., Barnett, A. G., and Woodward, A.: On the estimation of heat-intensity and heat-duration effects in time series models of temperature-related mortality in Stockholm, Sweden, Environ. Health, 11, 23, https://doi.org/10.1186/1476-069X-11-23, 2012.

Rooney, C., McMichael, A. J., Kovats, R. S., and Coleman, M. P. : Excess mortality in England and Wales, and in Greater London, during the 1995 heatwave, J. Epidemiol. Commun. H., 52, 482486, 1998.

Russo, S., Dosio, A., Graversen, R. G., Sillmann, J., Carrao, H., Dunbar, M. B., and Vogt, J. V.: Magnitude of extreme heat waves in present climate and their projection in a warming world, J. Geophys. Res.-Atmos., 119, 12500-12512, 2014.

Russo, S., Sillmann, J., and Fischer, E. M.: Top ten European heatwaves since 1950 and their occurrence in the coming decades, Environ. Res. Lett., 10, 124003, https://doi.org/10.1088/17489326/10/12/124003, 2015.

Schubert, S. D., Wang, H., Koster, R. D., Suarez, M. J., and Groisman, P. Y.: Northern Eurasian heat waves and droughts, J. Climate, 27, 3169-3207, 2014.

Smoyer-Tomic, K. E., Kuhn, R., and Hudson, A.: Heat wave hazards: an overview of heat wave impacts in Canada, Nat. Hazards, 28, 465-486, 2003.

Sousa, P. M., Trigo, R. M., Barriopedro, D., Soares, P. M., and Santos, J. A.: European temperature responses to blocking and ridge regional patterns, Clim. Dynam., 1-21, https://doi.org/10.1007/s00382-017-3620-2, online first, 2017.

Steadman, R. G.: The assessment of sultriness, Part I: A temperature-humidity index based on human physiology and clothing science, J. Appl. Meteorol., 18, 861-873, 1979.

Steadman, R. G.: A universal scale of apparent temperature, J. Clim. Appl. Meteorol., 23, 1674-1687, 1984.

Tibaldi, S., Tosi, E., Navarra, A., and Pedulli, L.: Northern and Southern Hemisphere seasonal variability of blocking frequency and predictability, Mon. Weather Rev., 122, 1971-2003, 1994.

Tomczyk, A. M. and Bednorz, E.: Heat waves in Central Europe and their circulation conditions, Int. J. Climatol., 36, 770-782, 2016.

Torrence, C. and Compo, G. P.: A practical guide to wavelet analysis, B. Am. Meteorol. Soc., 79, 61-78, 1998.
Trenberth, K. E. and Fasullo, J. T.: Climate extremes and climate change: The Russian heat wave and other climate extremes of 2010, J. Geophys. Res.-Atmos., 117, D17103, https://doi.org/10.1029/2012JD018020, 2012.

Trigo, R. M., García-Herrera, R., Díaz, J., Trigo, I. F., and Valente, M. A.: How exceptional was the early August 2003 heatwave in France?, Geophys. Res. Lett., 32, L10701, https://doi.org/10.1029/2005GL022410, 2005.

Van den Besselaar, E. J. M., Haylock, M. R., Van der Schrier, G., and Klein Tank, A. M. G.: A European daily high-resolution observational gridded data set of sea level pressure, J. Geophys. Res.-Atmos., 116, D11110, https://doi.org/10.1029/2010JD015468, 2011.

Van den Besselaar, E. J. M., Klein Tank, A. M. G., Van der Schrier, G., and Jones, P. D.: Synoptic messages to extend climate data records, J. Geophys. Res.-Atmos., 117, D07101, https://doi.org/10.1029/2011JD016687, 2012.

Vautard, R., Gobiet, A., Jacob, D., Belda, M., Colette, A., Déqué, M., and Halenka, T.: The simulation of European heat waves from an ensemble of regional climate models within the EUROCORDEX project, Clim. Dynam., 41, 2555-2575, 2013.

Vitart, F.: Monthly forecasting at ECMWF, Mon. Weather Rev., 132, 2761-2779, 2004.

Whan, K., Zscheischler, J., Orth, R., Shongwe, M., Rahimi, M., Asare, E. O., Seneviratne, S. I.: Impact of soil moisture on extreme maximum temperatures in Europe, Weather Climate Extremes, 9, 57-67, 2015.

WMO: Data, Climate, Guidelines on analysis of extremes in a changing climate in support of informed decisions for adaptation, available at: https://library.wmo.int/opac/index.php?lvl=notice_ display\&id=138\#.WkzgMq0cBGo, 2009.

WMO: Heatwaves and health: guidance on warning system development, WMO-No. 1142, World Meteorological Organisation, available at: http: //www.who.int/entity/globalchange/publications/ Web-release-WHO-WMO-guidance-heatwave-and-health. pdf?ua=_1 (last access: 3 January 2017), 2015.

Zhang, X., Hegerl, G., Zwiers, F. W., and Kenyon, J.: Avoiding inhomogeneity in percentile-based indices of temperature extremes, J. Climate, 18, 1641-1651, 2005. 